\title{
Diel migration and feeding patterns of the chaetognath, Sagitta friderici, off the west coast of South Africa
}

\author{
by Venetia Stuart' ${ }^{1}$ and Hans M. Verheye ${ }^{2}$
}

\begin{abstract}
The vertical distribution patterns of adult and juvenile Sagitta friderici were investigated over a $48 \mathrm{~h}$ period, using samples collected at different depth strata with an RMT $1 \times 6$ net. Juvenile chaetognaths were generally found at depths of less than $50 \mathrm{~m}$ throughout the day and night, and exhibited limited diel migration patterns. Adults, on the other hand, migrated more extensively and were generally found below $50 \mathrm{~m}$ during the day and scattered throughout the water column or near the surface at night. Using the mean depths at each sampling time, the migration patterns of adult chaetognaths closely followed that of the large calanoid copepods. Juvenile chaetognaths, on the other hand, showed no significant correlation with any group of copepods. The greatest proportion of chaetognaths with food in their guts were not found at the depths of maximum copepod abundance, suggesting that the chaetognaths had not been feeding at the depths where they were caught. There was little evidence of a diel feeding rhythm, with no significant difference between the number of prey per chaetognath during the day or night. The majority of food items ingested were copepods $(85.7 \%)$, while cannibalism on smaller chaetognaths occurred in $2.4 \%$ of the samples. The size of copepods consumed by adult chaetognaths was estimated from the width of the copepod mandibular blade, and was found to range from $0.16-1.96 \mathrm{~mm}$ prosome length. Although there was a large range of prey sizes which any given predator could consume, there was a clear trend of increasing prey size with increasing predator size. The energetic equivalent of ingesting a single copepod represented $47.4 \%$ of the body carbon of the juveniles, but only $16.7 \%$ for the adults. Consumption of two or more copepods increased this to $30.3 \%$ body carbon of the adults, but cannibalism on smaller chaetognaths represented an average of $46.8 \%$ of adult body carbon. Assuming equal handling costs, this implies that cannibalism is energetically much more advantageous for the adults than consuming copepods. Digestion times of copepod prey items were estimated from an exponential equation relating digestion time to temperature using values from the literature for six different chaetognath species. This yielded an ingestion rate of 0.5 copepods chaetognath ${ }^{-1} \mathrm{~d}^{-1}$, which resulted in $1.0-5.3 \%$ of the copepod standing stocks or $2.4-14.0 \%$ of the copepod production being consumed per day by the Sagitta friderici population.
\end{abstract}

\section{Introduction}

Chaetognaths are found in all oceans, and are usually relatively abundant, ranking second or third after the copepods (Raymont, 1983). All species are strictly carnivo-

1. Marine Biology Research Institute, Department of Zoology, University of Cape Town, Rondebosch, 7700, South Africa.

2. Sea Fisheries Research Institute, Private Bag X2, Rogge Bay, 8012, Cape Town, South Africa. 
rous (Feigenbaum and Maris, 1984) although there are occasional references to phytoplankton in chaetognath guts (e.g. Pearre, 1974; 1976) which may represent material ingested incidentally. The majority of chaetognath species feed mainly on copepods, and are therefore important in marine food webs.

Along the west coast of southern Africa is the highly productive Benguela upwelling region, which is one of the major recruitment areas for anchovy (Engraulis capensis) and pilchard (Sardinops ocellatus). This area has been intensively studied and much is known of the feeding behavior and population dynamics of the major components of the zooplankton, such as the copepods (Verheye, 1989; Peterson $e t$ al., 1990; Verheye, 1991; Armstrong et al., 1991) and euphausiids (Stuart, 1986, 1989; Pillar and Stuart, 1988; Stuart and Pillar, 1988; Gibbons et al., 1991). However, apart from a few early studies on the distribution of various chaetognath species (David, 1958; Heydorn, 1959), little is known about the chaetognath community of the Benguela upwelling region. For this reason a study was undertaken to examine the abundance, vertical distribution and in situ feeding behavior of the most common chaetognath species in the inshore waters (Sagitta friderici) in order to assess their importance as predators within the zooplankton community, and to determine their impact on the copepod community.

\section{Methods}

a. Collection of samples. Data were obtained from 40 samples, collected approximately every $6 \mathrm{~h}$ over a $48 \mathrm{~h}$ period ( 8 sampling times), from 5 different depth strata. These were collected during a time series cruise aboard the R.S. Africana from 26-28 May 1984, in the St Helena Bay region on the west coast of South Africa (Fig. 1). Sampling was confined to a $1 \times 1$ nautical mile $\left(3.2 \mathrm{~km}^{2}\right)$ grid NW of Elands Bay in approximately $70 \mathrm{~m}$ of water. At each station zooplankton were collected with an obliquely towed $1 \mathrm{~m}^{2}$ multiple opening-closing rectangular midwater trawl fitted with six $200 \mu \mathrm{m}$ meshed nets (RMT-1 $\times 6$ ). The net was fished at an angle of $45^{\circ}$ by maintaining a towing speed of $1.5-2.0 \mathrm{~m} \mathrm{~s}^{-1}$. Depth, temperature, flow, net angle and net operations were monitored electronically with a De Bruyn Universal Underwater Unit (Sea Fisheries Research Institute, Internal Report). The first net was fished from the surface to near the bottom to stabilize the net during descent. The other five nets collected zooplankton during the ascent in five depth strata from near the bottom (65-72 m) to the surface. At least one sample was collected above, one within and one below the thermocline. Individual tows were kept short to avoid clogging caused by the relatively low ratio of net mesh open-area to mouth area $(R=3)$. All zooplankton samples were preserved in borax-buffered $5 \%$ formaldehyde solution.

b. Laboratory processing of samples. Each zooplankton sample was halved with a Folsom plankton splitter. Data on the numerical abundance of copepods were obtained from one half of the sample by replicate subsampling. The samples were 


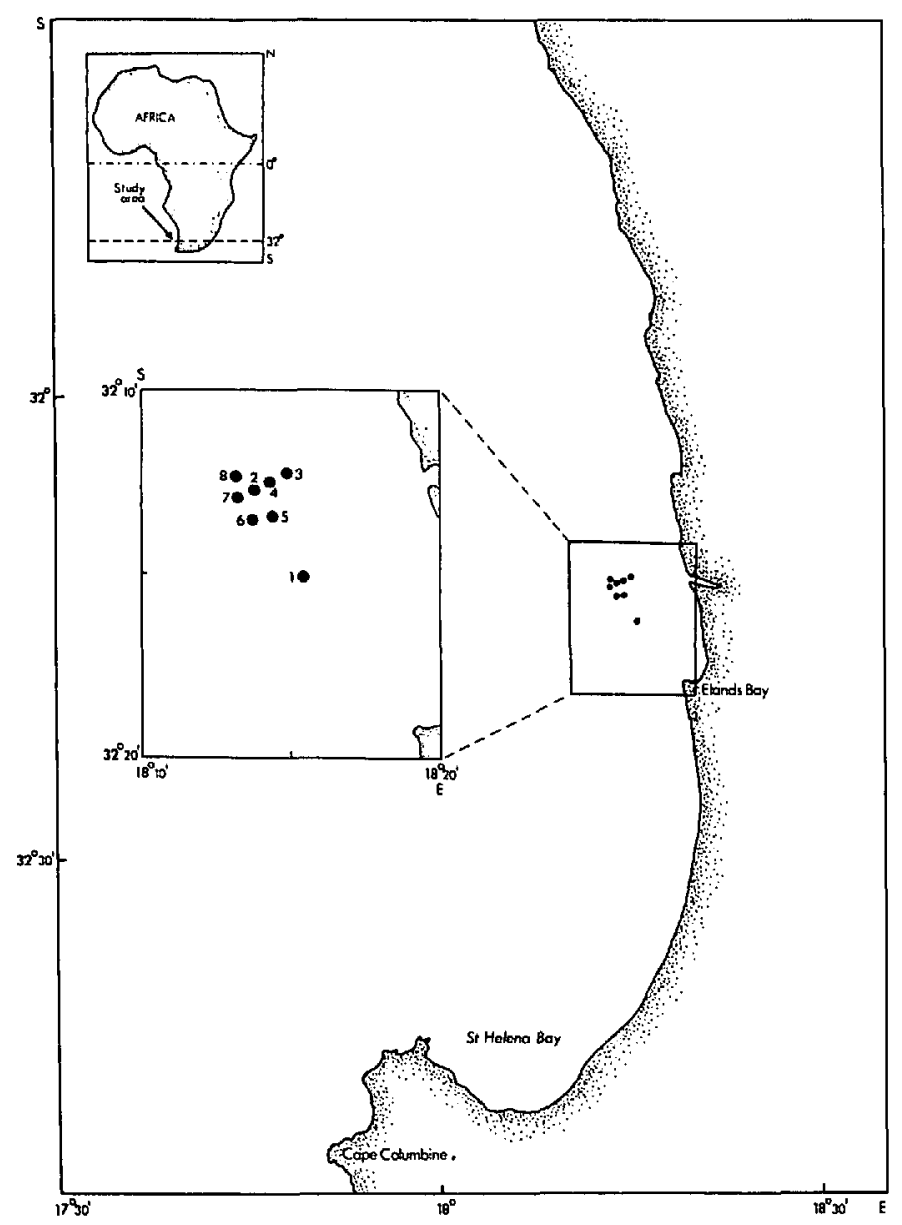

Figure 1. Map of the study area indicating the position of the 8 sequential time-series stations.

poured into graduated measuring cylinders and allowed to settle for $24 \mathrm{hrs}$. The settled volume was read and preservative decanted or added to make a diluted volume of $10 \times$ the settled volume. After resuspending the zooplankton through air bubbling, $2 \mathrm{ml}$ subsamples were removed with a modified piston pipette for counting. At least three subsamples were drawn from each sample, and all copepods counted in four categories: cyclopoid copepods, essentially Oithona spp. (0.39-0.42 mm prosome length); small calanoids, mostly Paracalanus, Clausocalanus and Ctenocalanus, and juvenile Metridia lucens $(0.42-0.98 \mathrm{~mm})$; large calanoids, mostly $\mathrm{C} 3-\mathrm{C} 5$ and adult stages of Calanoides carinatus and adult Metridia lucens $(0.90-2.20 \mathrm{~mm})$ and very large calanoids, consisting entirely of Rhincalanus nasutus pre-adults and adults $(>2.40 \mathrm{~mm}$ ). Successive subsamples were drawn until at least 50 specimens in each group were enumerated. 
The other half of the sample was split again with a Folsom plankton splitter until there were $c a 100$ chaetognaths per subsample. The total body length (excluding tail fin) of all specimens was measured in $1 \mathrm{~mm}$ size-classes and the stage of maturity determined according to the development of the ovaries (Zo, 1973): stage I animals had no visible ovaries; stage II had developing ova of different sizes, but no mature ova and stage III had one or more mature ova.

Vertical distributions of adult (stages II and III) and juvenile (stage I) chaetognaths and the copepods were determined by correcting the counts in each case for volume filtered and fraction of the sample analyzed. "Mean depths" of each group were calculated at each time interval according to Pearre (1973):

$$
\bar{d}=\Sigma n_{i} d_{i} / \Sigma n_{i}
$$

where $n_{i}$ is the number of individuals per $\mathrm{m}^{3}$ at that depth-range and time and $d_{i}$ is the mid-point of the depth-range.

Chaetognath specimens which were suspected of containing food material were transferred into separate containers. Each individual was measured, and the position of food in the gut recorded on a scale of 1 to 3, according to Øresland (1987): position 1 , forward; position 2, middle; position 3, posterior (food material in position 3 was often only confirmed after dissection because of the advanced stage of digestion). The rear gut was then completely dissected out using sharp needles and placed in a drop of glycerine on a glass slide. Here the gut contents were squeezed out and examined under high power. The proportion of the population at each time interval containing food in their guts, the food containing ratio, (FCR = no. chaetognaths containing food/total no. chaetognaths $\times 100$ ) was calculated as well as the number of prey items per chaetognath (NPC $=$ total no. prey items/total no. chaetognaths). The stage of digestion of the prey items (predominantly copepods) was also determined on a scale of 1-3 according to Sullivan (1977): stage 1, virtually undigested; stage 2 , exoskeleton partly compacted and tissue digested; stage 3 , only mandibles and setae from legs remain.

Care was taken to locate the copepod mandibles which were measured under $100 \times$ magnification. The number of copepods consumed was estimated from the total number of mandible pairs per gut. When only copepod remains or a single mandible were recovered, these were considered to represent one copepod and when several mandibles were present, these were matched by size and the characteristics of the toothed edge of the mandibular blade. Mandible width was converted to copepod prosome length using a regression from a previous study carried out in the southern Benguela region (Stuart and Pillar, 1990), but in several cases of relatively intact small copepods, the prosome length was measured directly.

Daily ingestion rates of adult chaetognaths consuming copepods were estimated 
from the following equation, modified from that of Bajov (1935):

$$
I=N_{d} h_{d} / t_{D}+N_{n} h_{n} / t_{D}
$$

where $I$ = ingestion rate (copepods chaetognath ${ }^{-1} \mathrm{~d}^{-1}$ ), $N_{d}$ and $N_{n}=$ number of copepods per chaetognath gut during the day and night respectively (obtained by integrating the area under the curve of NPC vs. time), $h_{d}$ and $h_{n}=$ number of hours of daylight or darkness, taken from sunrise to sunset, and $t_{D}=$ digestion time in hours.

Cannibalism on smaller chaetognaths was detected by the presence of chaetae (hooks) of the prey, which were also measured. The size of the prey was established from a regression relating maximum chaetae length to total body length. However, Pearre (1980) noted a better relationship between prey and predator sizes when chaetognath head width and prey width were used, so the relationships between chaetognath body length and head width (chaetae in closed position), as well as copepod prosome length to copepod width were determined using a size range of chaetognaths and a selection of copepods collected during the course of the study. Length/weight relationships were obtained from freshly collected live specimens which were measured, rinsed briefly in distilled water, blotted dry and weighed on a Sartorius microbalance to the nearest $\mu \mathrm{g}$ for wet weight determination. These samples were then placed in small aluminium dishes, dried in an oven at $60^{\circ} \mathrm{C}$ for $24 \mathrm{~h}$ and weighed as before for dry weight determination. Carbon and nitrogen content of six replicate samples, each containing $20-40$ adult chaetognaths, was also measured using a Heraeus $\mathrm{CHN}$ analyzer.

\section{Results}

a. Population structure and vertical distribution. The average population sizedistribution was obtained from the mean number of chaetognaths in each size class over all depths and sampling times, and is illustrated in Figure 2. Juveniles, with no evidence of ovary development (stage I), generally had a total length of less than $8 \mathrm{~mm}$ and were present in relatively low numbers throughout the water column (range $0.23-9.3 \mathrm{~m}^{-3}$ ). It is possible that some of the smaller individuals $(<4 \mathrm{~mm}$ total length) may have escaped through the mesh of the $200 \mu \mathrm{m}$ net since the mean length/width ratio of Sagitta friderici was 19.4:1. Adults with mature (stage III) or maturing (stage II) ovaries made up the bulk of the samples with numbers ranging from 26.4-197.9 $\mathrm{m}^{-3}$. The chaetognath population as a whole had a unimodal size-frequency distribution with adults reaching a maximum length of $\sim 16 \mathrm{~mm}$.

Temperature/depth profiles remained constant throughout the study, varying by less than $0.6^{\circ} \mathrm{C}$ at any one depth interval. Surface temperatures of $c a 15^{\circ} \mathrm{C}$ and bottom waters of $c a 10^{\circ} \mathrm{C}$ were recorded, with a well-developed thermocline between $30-55 \mathrm{~m}$. Vertical migration patterns of adult (stages II and III) and juvenile (stage I) Sagitta friderici were examined in relation to that of the copepods, by computing the 


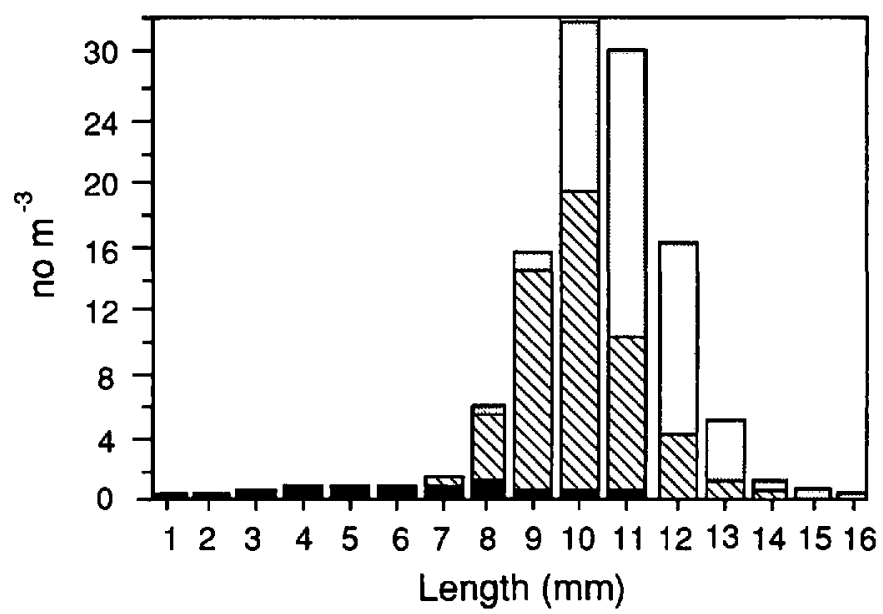

Figure 2. Size-frequency distribution of Sagitta friderici (average of all samples) according to stage of development (I, solid black; II, oblique lines; III, stippled).

mean depths of each group at each time interval using Eq. 1. Since chaetognath and copepod numbers varied from time to time, the vertical distribution patterns have been expressed on a relative scale (Fig. 3). This variation in total water column abundance may be due to some animals migrating below the deepest sample stratum during the day, but since this was not consistent, it is likely that horizontal patchiness played a greater role. Juvenile chaetognaths exhibited only limited diel migration patterns, with individuals occurring slightly deeper during the day and shallower at night. Adults, on the other hand, showed more distinct diel migration patterns, with the majority of the population being found in the cool deeper waters $(>50 \mathrm{~m})$ during daylight hours, and scattered throughout the water column at night (Fig. 3). These migration patterns are also similar to that of the copepods, although there was no significant correlation between the mean depths of the adult chaetognaths and that of the copepods ( $p=0.22$, Spearman's Rank Correlation), or between that of the juvenile chaetognaths and the copepods $(p=0.87$ ). However, if the mean depths of each category of copepods is calculated separately (Fig. 4), there was a very high correlation between the migration patterns of adult chaetognaths and the large $(0.90-2.20 \mathrm{~mm})$ calanoid copepods $(p=0.00)$, as well as the small $(0.42-0.98 \mathrm{~mm})$ calanoid copepods $(p=0.03)$, but not the cyclopoid copepods $(p=0.45)$. Juvenile chaetognaths occupied a somewhat shallower zone, and exhibited limited vertical migration patterns which were not significantly related to any group of copepods ( $p=0.70$, cyclopoids; $p=0.55$, small calanoids; $p=0.18$, large calanoids). During the first two time intervals, juveniles were only caught at two depths, so the calculated mean depths had large variances. The mean depths occupied by adult and juvenile chaetognaths and the three categories of copepods were significantly different ( $p=0.01$, one-way ANOVA), with small and large calanoid copepods and 

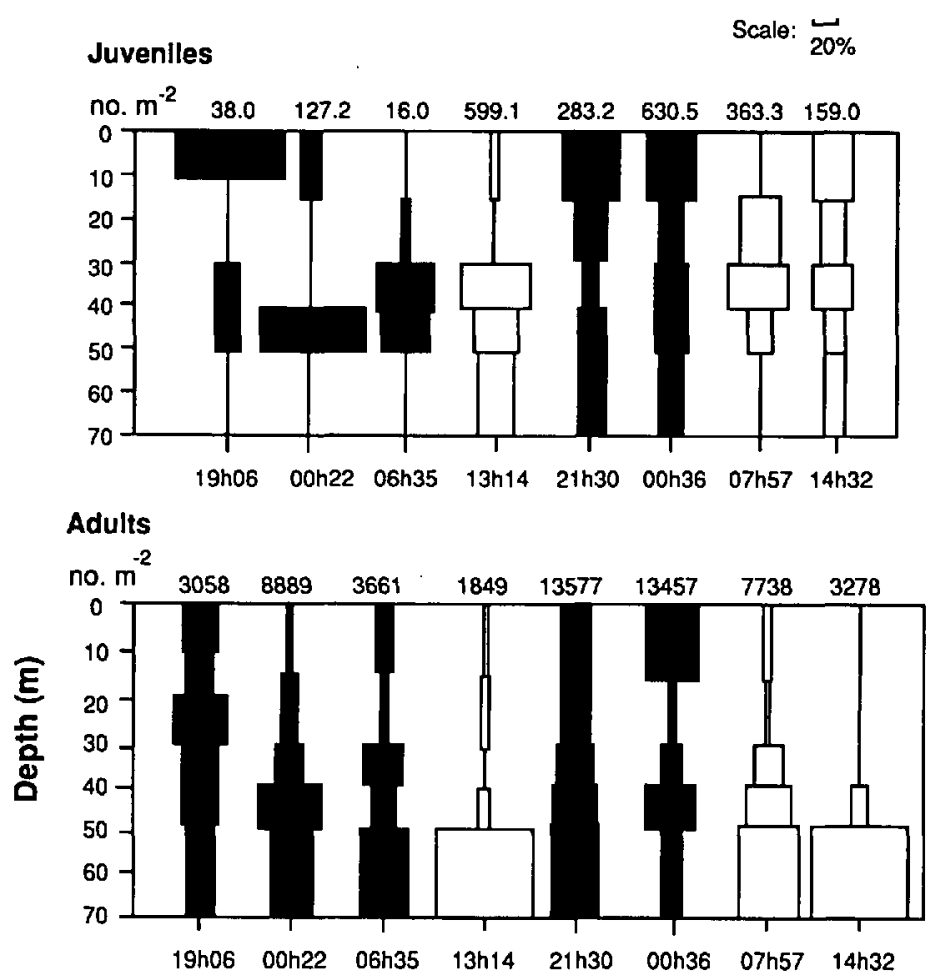

Copepods
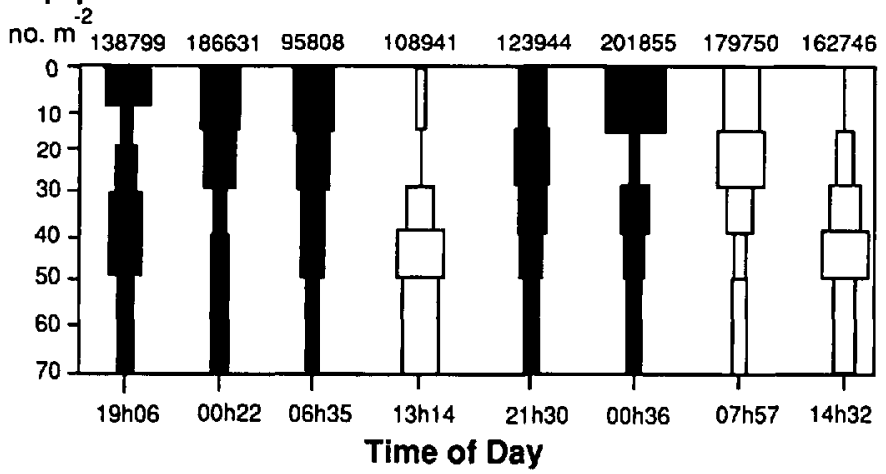

Figure 3. Vertical distribution of juvenile and adult Sagitta friderici and copepods (cyclopoids, small and large calanoids) from the time series of eight RMT- $1 \times 6$ hauls, 26/5/84-28/5/84, expressed as a relative percentage of total numbers at each sampling time. Dark shaded boxes represent samples taken at night, while unshaded boxes represent day samples. Actual numbers $\mathrm{m}^{-2}$ at each sampling time are also indicated. 
a)

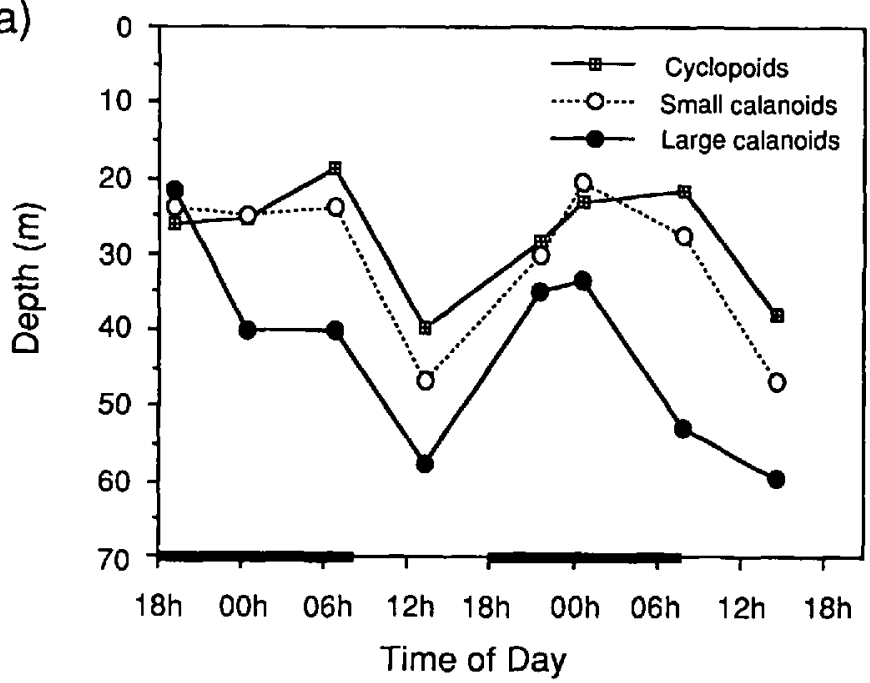

b)

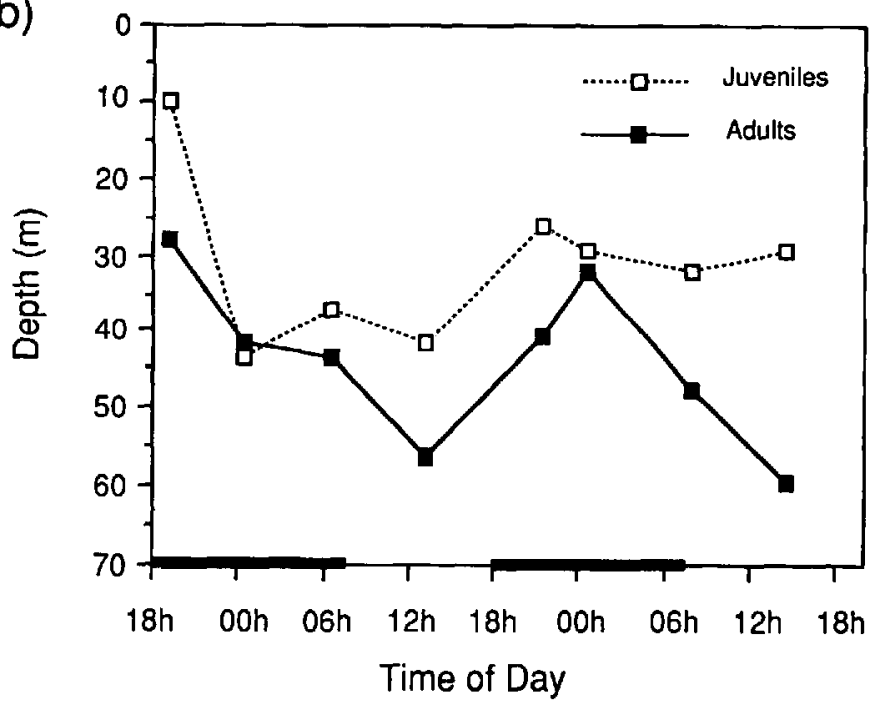

Figure 4. Mean depths of (a) cyclopoid, small calanoid and large calanoid copepods and (b) juvenile and adult Sagitta friderici calculated from numbers $\mathrm{m}^{-3}$ at each depth and sampling time. Solid dark bars represent hours of darkness.

juvenile chaetognaths forming a homogeneous group shared by cyclopoid copepods on the one side and adult chaetognaths on the other.

Total chaetognath biomass at each time interval was calculated using the length/ dry weight regression given in Table 1 , and ranged from $3.44-37.86 \mathrm{mg} \mathrm{m}^{-3}$. Variations in biomass are probably due to horizontal patchiness, since samples were 
Table 1. Regression equations and conversion factors used for calculating various relationships between Sagitta friderici size and copepod size. DW = dry weight (mg); L = total length excluding tail fin $(\mathrm{mm}) ; \mathrm{HW}=$ head width $(\mathrm{mm}) ; \mathrm{CL}=$ maximum chaetae length $(\mathrm{mm}) ; \mathrm{PL}=$ prosome length $(\mathrm{mm}) ; \mathrm{BW}=$ maximum body width $(\mathrm{mm})$; and $\mathrm{MW}=$ mandible width $(\mathrm{mm})$.

$\begin{array}{llll}\text { Parameters measured } & r^{2} & \text { Reference }\end{array}$

\section{Sagitta friderici}

Length:dry weight

Length:head width

Chaetae length:Length

$\mathrm{HW} / \mathrm{L}$ ratio

Carbon as \% DW

DW as \% wet wt

$\begin{array}{lcc}\text { DW }=0.00021 \mathrm{~L}^{2.870} & 0.97 & \text { This study } \\ \text { HW }=0.110+0.041 \mathrm{~L} & 0.86 & \text { This study } \\ \text { L }=50.017 \mathrm{CL}^{1.626} & 0.96 & \text { This study } \\ 0.0526 \pm 0.009 \text { (S.D.) } & - & \text { This study } \\ 27.87 \pm 0.58 \text { (S.D.) } & - & \text { This study } \\ 7.58 \pm 1.21 \text { (S.D.) } & - & \text { This study }\end{array}$

Copepods

Length:width

$\mathrm{BW}=0.350 \mathrm{PL}^{0.767}$

Length:DW

$\mathrm{DW}=19.425 \times 10^{-3} \mathrm{PL}^{2.590}$

0.94

This study

Mandible W:Length

$\mathrm{PL}=11.491 \mathrm{MW}^{0.947}$

$\overline{0.92}$

James (1987)

0.92 Recalculated from

Stuart \& Pillar (1990)

Carbon as \% DW

$40 \%$

- Parsons et al. (1984)

Predator size:prey size

$\mathrm{HW}: \mathrm{BW}$ ingested

$\mathrm{BW}=0.4433 \mathrm{HW}^{0.792}$

0.066 This study

b. Feeding periodicity. Data for feeding by juvenile chaetognaths was too limited to infer any diel feeding rhythms, but was used for predator-prey size-relationships. The variations in feeding intensity by adult chaetognaths throughout the $48 \mathrm{~h}$ sampling period are shown in Figure 5. There is limited evidence of a diel feeding rhythm: the greatest proportion of individuals contained food in their guts in the late

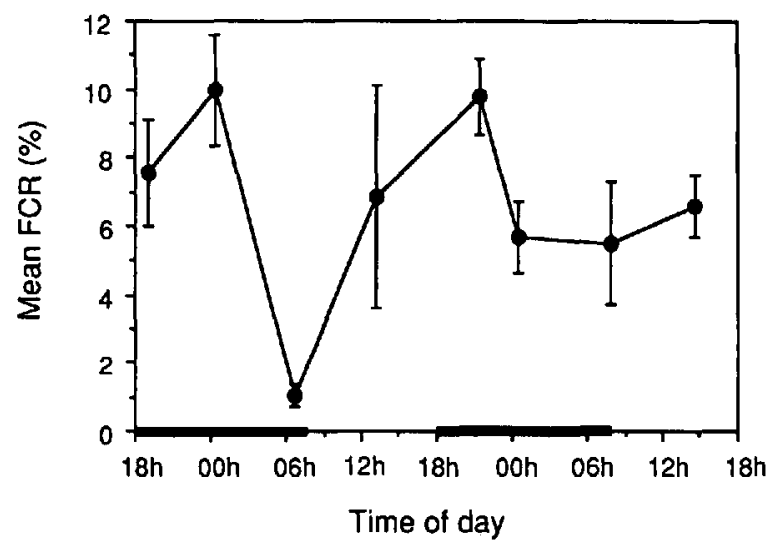

Figure 5. Mean food containing ratio (FCR) \pm S.E. of adult Sagitta friderici over the entire water column at each time interval. Solid dark bars represent hours of darkness. 


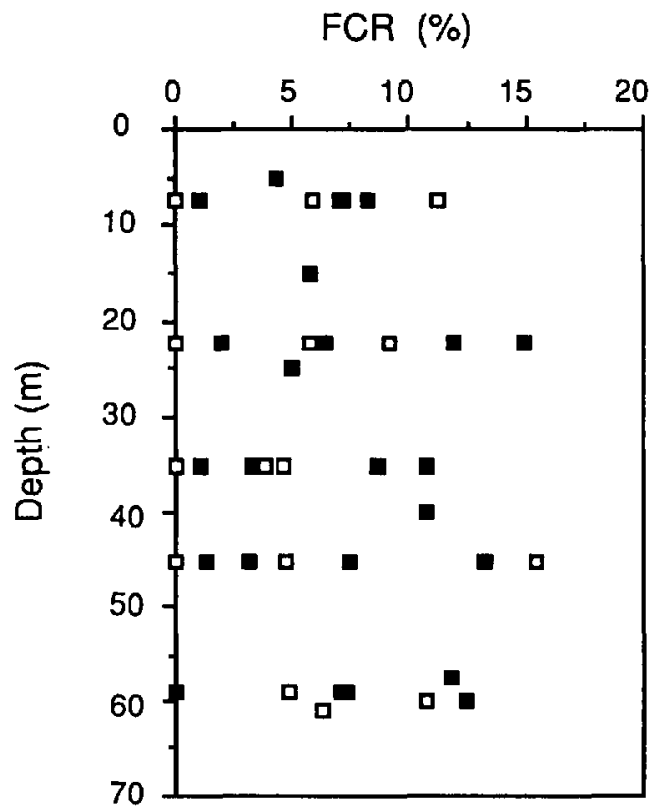

Figure 6. Food containing ratio (FCR) of adult Sagitta friderici at each depth sampled during the day (unshaded squares) and at night (solid squares).

afternoon/early evening while very few individuals contained food material just before dawn. However, it should be noted that samples from $06 \mathrm{~h} 00$ during the first night were slightly damaged by the nets (towing speed too fast?) so the FCR for this time interval could perhaps be higher. There was no significant difference between the number of prey per chaetognath during the day or night $(p>0.05$, MannWhitney U-test). As can be seen from Figure 6, many adult chaetognaths contained food in their guts during the daylight hours. It is also interesting to note that the proportion of chaetognaths with food in their guts did not bear any relation $\left(r^{2}=0.11\right)$ to total copepod abundance at the corresponding depth (Fig. 7). Similar results were obtained when FCR was plotted against small calanoid copepods $\left(r^{2}=0.13\right)$ and large calanoid copepods $\left(r^{2}=0.01\right)$.

c. Composition of the diet. A total of 3805 chaetognaths were examined for the presence of food in their guts of which 238 individuals contained food ( 283 prey items). Of these, 10 prey items were in position 1 and in an early stage of digestion, so they were omitted from the analysis because of the possibility of cod-end feeding. Food remains were grouped into five categories: copepods or copepod nauplii, other crustaceans such as amphipods or cirripede nauplii, chaetognaths, globules of colorless jelly $(200-400 \mu \mathrm{m})$, and other unidentifiable material such as detritus. The proportions of these food items in the guts of adult and juvenile chaetognaths is given in Table 2. Large globules of yellow oil were frequently encountered in the guts, 


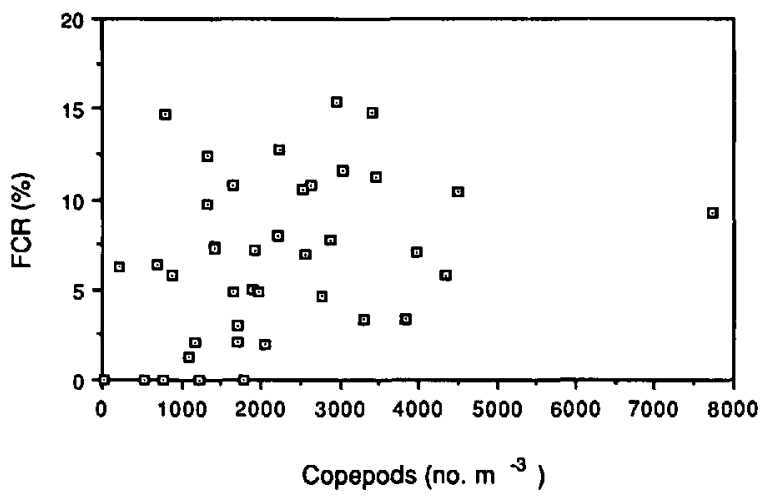

Figure 7. Relationship between copepod abundance (no. $\mathrm{m}^{-3}$ ) and the food containing ratio (FCR) of adult Sagitta friderici at each depth and sampling time.

which resembled the oil from oil-rich copepods (Sameoto, 1987). This oil has been found to remain in the guts of the chaetognath Eukrohnia hamata to some degree after the fecal pellet has been voided (Øresland, 1987), therefore the presence of oil alone was not interpreted as food remains (10 individuals in the present study). Copepods and copepod nauplii were the principal component of the diet in the adults $(85.75 \%)$ as well as the juveniles $(71.4 \%)$. Only three whole nauplii were recovered, but since the smallest copepod present in the water column was Oithona sp. which had a mean prosome length of $0.403 \mathrm{~mm}$, any mandibles corresponding to smaller copepods may also be attributed to nauplii or copepodite stages. Other crustaceans such as amphipods and cirripede nauplii represented a further $0.8 \%$ of the diet in adult chaetognaths. Cannibalism on other chaetognaths constituted $2.4 \%$ of prey items ingested by adult chaetognaths, but no chaetognaths were recovered from juvenile guts, which may be a result of the small sample size. Only 21 prey items were recovered from a total of 544 juvenile chaetognaths indicating either a low feeding rate or it may reflect a greater dependence on soft-bodied prey which were

Table 2. Composition of the gut contents of adult and juvenile Sagitta friderici by number and percentage.

$\begin{array}{cccccccc}\begin{array}{c}\text { Number } \\ \text { examined }\end{array} & \begin{array}{c}\text { Mean } \\ \text { size }\end{array} & \begin{array}{c}\text { Total } \\ \text { prey }\end{array} & \text { Copepods } & \begin{array}{c}\text { Chaetog- } \\ \text { naths }\end{array} & \begin{array}{c}\text { Other } \\ \text { Crus- } \\ \text { taceans }\end{array} & \text { Jelly } & \begin{array}{c}\text { Unidenti- } \\ \text { fied }\end{array} \\ 3261 & 11.48 & 252 & 216 & 6 & 2 & 10 & 18 \\ - & - & - & 85.5 \% & 2.4 \% & 0.8 \% & 4.0 \% & 7.1 \%\end{array}$

Adults

Numbers

Percent

$85.5 \%$

$2.4 \%$

$0.8 \%$

$4.0 \%$

$7.1 \%$

Juveniles

Numbers 
Table 3. Mean number and size (prosome length) \pm 1 S.D. of copepods ingested by different size-classes of chaetognaths (total length) with copepod mandibles in their guts, as well as the percentage of all chaetognaths with food in their guts displaying cannibalism. $N=$ number of chaetognaths with copepod mandibles in their guts.

$\begin{array}{lcccc}\begin{array}{l}\text { Length size } \\ \text { class }(\mathrm{mm})\end{array} & \begin{array}{c}\text { Mean no. } \\ \text { Copepods }\end{array} & \begin{array}{c}\text { Mean Copepod } \\ \text { size }(\mathrm{mm})\end{array} & N & \text { \% cannibalism } \\ 3-4.99 & 1 \pm 0 & 0.55 \pm 0.25 & 2 & 0 \\ 5-6.99 & 1 \pm 0 & 0.54 \pm 0.30 & 2 & 0 \\ 7-8.99 & 1.22 \pm 0.66 & 0.56 \pm 0.37 & 5 & 0 \\ 9-10.99 & 1.28 \pm 0.46 & 0.80 \pm 0.42 & 47 & 2.86 \\ 11-12.99 & 1.33 \pm 0.77 & 0.96 \pm 0.48 & 68 & 2.04 \\ 13-14.99 & 1.57 \pm 0.75 & 0.94 \pm 0.33 & 19 & 28.57\end{array}$

not recovered. Single prey items accounted for $85 \%$ of the diet of Sagitta friderici, while $15 \%$ of the individuals, mostly larger specimens (Table 3 ), contained multiple prey. The mean stage of digestion did not differ significantly $(p>0.001$, MannWhitney U-test) between daytime ( $2.78 \pm 0.58$ S.D.) or nighttime samples $(2.81 \pm 0.44$ S.D.) suggesting intermittent feeding during the day and night. Cannibalism was observed only in adult chaetognaths greater than $10.7 \mathrm{~mm}$ total length. Although only very few data points were obtained, there is an apparent increase in the degree of cannibalism with increasing predator size (Table 3).

The relationship between predator size and size of copepod prey consumed was investigated by converting copepod mandible width to copepod prosome length, width or dry weight using the regression equations presented in Table 1. From these relationships, the Sagitta friderici population was found to have consumed a wide size-range of copepods, from $0.16-1.96 \mathrm{~mm}$ prosome length (Fig. $8 \mathrm{a}$ ). This can be compared to the size-distribution of copepods in the water column (Fig. 8b) which was obtained by measuring the prosome length of 800 copepods (100 from the copepod maxima at each time interval). It can be seen that the range of copepod sizes consumed by the chaetognath population is similar to that in the water column, apart from the absence of the very large Rhincalanus nasutus ( 2.4 to $3.9 \mathrm{~mm}$ prosome length) in the gut samples and the presence of copepods less than $0.4 \mathrm{~mm}$ prosome length, which were absent from the water column sample. Since a copepod of $0.4 \mathrm{~mm}$ prosome length has a width of $c a 170 \mu \mathrm{m}$ (Table 1), these smaller individuals were obviously not efficiently retained by the $200 \mu \mathrm{m}$ nets. However, the relative proportion of copepods of different sizes consumed by the chaetognath population differs from that in the water column. A dominance of $0.7-0.9 \mathrm{~mm}$ prosome length copepods was found in the chaetognath guts. This size fraction was less dominant in the water column, indicating a preference for copepods in this size range. These include small calanoid copepods such as Paracalanus, Ctenocalanus, C1-C2 Calanoides carinatus, Clausocalanus and juvenile Metridia lucens. Copepods with a prosome length of $1.6 \mathrm{~mm}$ (mainly pre-adult Calanoides carinatus and adult Metridia lucens) were also 


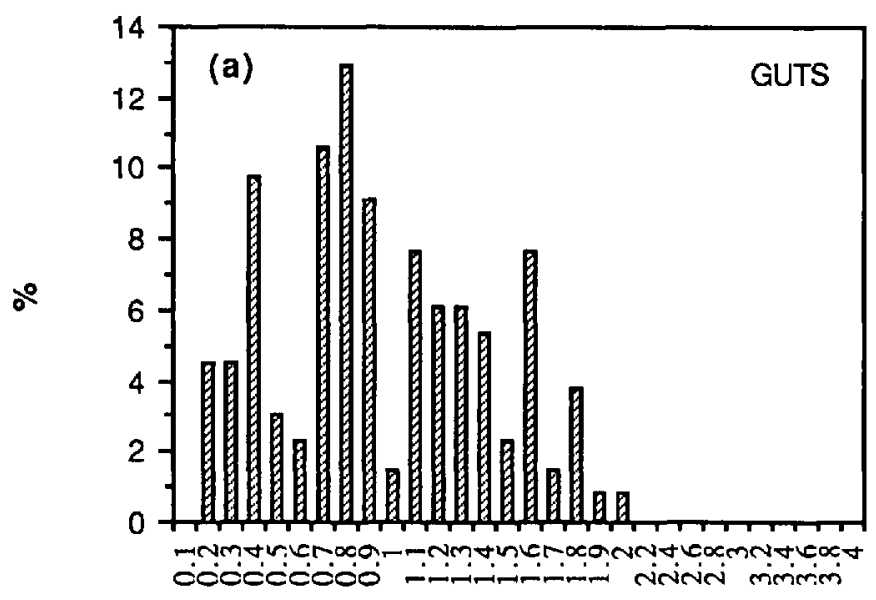

Copepod prosome length $(\mathrm{mm})$

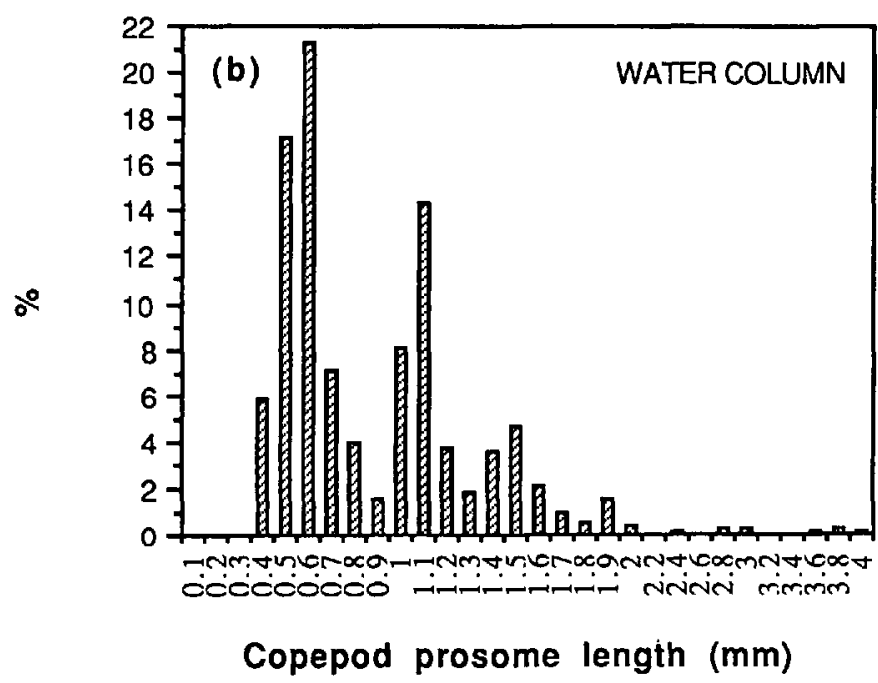

Figure 8. Size-frequency distribution of copepods (a) in the guts of Sagitta friderici, and (b) in the water column during the study period.

found in the gut samples at higher than ambient proportions. Other sizes of copepods were consumed in roughly similar proportions to those in the water column.

Any given chaetognath could ingest a wide range of copepod sizes (Fig. 9). However, there is a clear trend of increasing prey size with increasing predator size if the chaetognaths are divided into length or head width size-classes and the mean prey size calculated (Table 3, Table 4). Chaetognath head widths and copepod body widths were calculated using the regression equations in Table 1. 


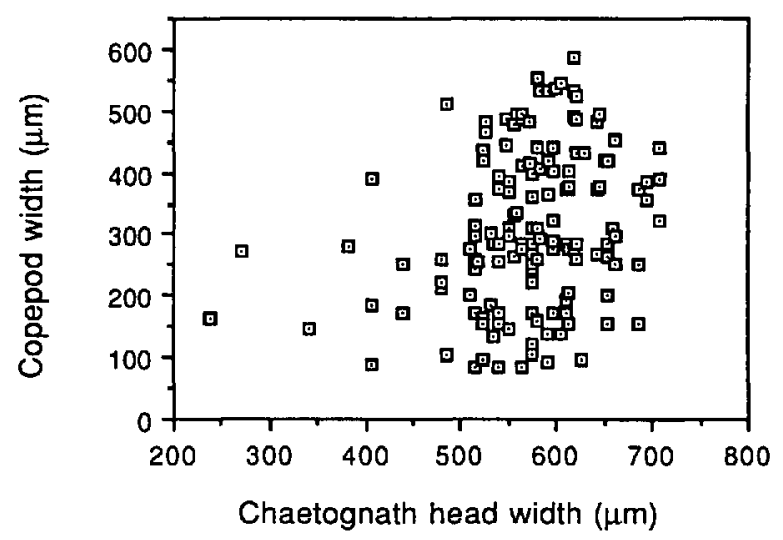

Figure 9. Size of copepods (measured as body width) consumed by different sized Sagitta friderici (measured as head width).

The average carbon value of copepod and chaetognath prey consumed by Sagitta adults was calculated from the equations in Table 1, and expressed as percent body carbon ingested (Table 5). Juvenile chaetognaths ingested an average of $47.4 \%$ of their body carbon when preying on single copepods, in contrast to $16.7 \%$ body carbon for the adults. However, in cases of multiple ingestion of copepods, this resulted in a consumption of $30.3 \%$ body carbon for adult chaetognaths and $42.8 \%$ for the juveniles. Furthermore, when adult Sagitta fed cannibalistically on smaller chaetognaths, they consumed $46.8 \%$ of their body carbon at one time, indicating that cannibalism is energetically much more advantageous for adults than ingesting copepods, assuming equal handling costs.

\section{Discussion}

a. Vertical migration. Juvenile Sagitta friderici exhibited limited diel vertical migration, generally remaining above the thermocline $(<50 \mathrm{~m})$, throughout the day and night, centered around a mean depth of $c a 30 \mathrm{~m}$. This is similar to the distribution

Table 4. Mean size (body width) \pm 1 S.D. of copepods ingested by different size classes of chaetognaths (head width). $N=$ number of chaetognaths with copepod mandibles in their guts.

Head width size class $(\mathrm{mm})$ Copepod width consumed

$0.213 \pm 0.095 \quad 2$

$0.239 \pm 0.144$

$0.303 \pm 0.123$

$0.341 \pm 0.127$ 
Table 5. Mean carbon equivalents of copepod and chaetognath prey items ingested by juvenile and adult Sagitta friderici, expressed as \% body carbon \pm 1 S.D.

Ingestion of Copepods
$\%$ body carbon

Single prey

Juveniles

Adults

Multiple prey

Juveniles

Adults
$47.4 \pm 48.9$

$16.7 \pm 16.3$

$42.8 \pm 40.2$

$30.3 \pm 27.4$
Ingestion of Chaetognaths

$\%$ body carbon

patterns of immature $S$. elegans which also remain near the surface throughout the day and night (Pearre, 1973; Sullivan, 1980; Lough and Trites, 1989). Adult Sagitta friderici, on the other hand, underwent more extensive migrations from near the bottom ( $\mathrm{ca} 70 \mathrm{~m}$ ) during the day, to the surface waters at night, which closely mirrored the migration patterns of the large calanoid copepods. By remaining in the cool, deep waters during the day, Sagitta friderici aduits are perhaps able to reduce their specific metabolic demands. This ontogenetic migration of chaetognaths has been noted by several authors (Pearre, 1973; Sullivan, 1980; Cheney, 1985; Sameoto, 1987; Lough and Trites, 1989) and appears to be common in most chaetognath species studied (Sameoto, 1987), as well as in other zooplanktonic organisms such as copepods (Huntley and Brooks, 1982; Verheye, 1989; Verheye and Field, 1991) and euphausiids (eg. Pillar et al., 1989). Younger stages frequently exhibit little or no vertical migration patterns, while the more mature individuals migrate extensively throughout the water column. Pearre (1979) proposed a model of vertical migration in which hunger acted as a mediator and light as a synchronizer of vertical movements. Lough and Trites (1989), on the other hand, believe that light plays a primary role in vertical migration patterns, with hunger or satiation influencing the timing and vertical range. In the present study, adult Sagitta friderici exhibited a downward migration or "midnight sinking" (Pearre, 1973) during the first night (Fig. $3,00 \mathrm{~h} 22)$, while during the second night ( $00 \mathrm{~h} 36)$, a large proportion of the population was aggregated near the surface. According to Pearre (1973) the time spent in the upper waters is only concerned with hunting, and the "midnight sinking" is a removal of satiated feeders from the surface as has also been found in copepods and euphausiids (Simmard et al., 1985; 1986). However, interpretation of vertical migration patterns should be made with caution since in the present study feeding did not only occur at the surface but also at depth. In addition, since vertical migration is generally not synchronous among individuals for most species (Pearre, 1973; 1979), numbers alone cannot adequately describe the actual path of vertical migrations. 
b. Food and feeding. The NPC of Sagitta friderici was relatively low $(0.01-0.18)$ during the course of this study, which may indicate generally low feeding rates for this species in the cool neritic waters of the west coast of South Africa. Stone (1965) also noted that the number of chaetognaths with identified gut contents constituted only ca $3 \%$ of the total specimens captured off the east coast of South Africa, and that $S$. enflata in cold neritic waters contained fewer food items than the same species in warmer oceanic waters. However, it is also possible that the low NPC is a reflection of the low copepod densities (average 1409-2968 $\mathrm{m}^{-3}$, Table 6). Pearre (1976) recorded similar numbers of prey per chaetognath $(0.05-0.15)$ for three species in the western Mediterranean Sea, although no copepod densities are available for comparison, while Sameoto (1987) recorded $0.15-0.3$ prey per chaetognath for Sagitta elegans at copepod densities of $27-1006 \mathrm{~m}^{-3}$ and 0.09 for $S$. minima at copepod densities of $63-1649 \mathrm{~m}^{-3}$. Although several authors have found no relationship between feeding rates of chaetognaths and prey abundance (Pearre, 1973; Nagasawa and Marumo, 1972; Kuhlmann, 1977), as in the present study, this only appears to hold true at low prey densities. At very high prey densities, high NPC's are frequently recorded: e.g. Gibbons (1991) obtained NPC's of 0.7-0.95 for S. serratodentata tasmanica in the southern Benguela region where the highest copepod densities reached $\mathrm{ca} 8000 \mathrm{~m}^{-3}$ (Gibbons, pers comm.) while Sullivan (1980) obtained NPC's of 1.2 for Eukrohnia hamata at prey densities of $10000 \mathrm{~m}^{-3}$.

Copepods formed the major prey of Sagitta friderici, representing $85.7 \%$ of the diet, which is similar to that of many other chaetognath species (Sullivan, 1980; Feigenbaum, 1979, 1982; Drits and Utkina, 1988) as well as to Sagitta friderici along the east coast of South Africa which contained $90.2 \%$ copepods in its diet (Stone, 1965). The size-range of copepods ingested by adult Sagitta covered the range of copepods in the water column (apart from the large Rhincalanus nasutus which were not consumed), but the proportions of each size-class ingested differed from that in the water column. There was a preference for copepods in the size classes $0.7-0.9 \mathrm{~mm}$ and $1.6 \mathrm{~mm}$ prosome length, which were found in relatively low proportions in the water column. Similarly, Gibbons (1991) noted that $S$. serratodentata tasmanica from the Benguela region also consumed copepods between 0.8 and $1.0 \mathrm{~mm}$ at well above ambient proportions. It should be borne in mind that the proportions of copepods in the water column are somewhat distorted by the inefficient retention of copepods $<0.4 \mathrm{~mm}$ prosome length by the $200 \mu \mathrm{m}$ nets. Nevertheless, copepod prey appear to be selected on the basis of size, with large chaetognaths, on average, consuming larger prey than smaller ones (Table 3, Table 4) (see also Reeve, 1980; Pearre, 1980; Øresland, 1987). The predator size/prey size regression, in terms of predator head width and prey body width (Table 1), indicates that Sagitta friderici are consuming prey with a body width of approximately half their own head width. The ' $b$ ' value is most similar to that of $S$. minima (see Pearre, 1980), although this species consumed much larger prey. The Sagitta friderici recorded by 
Pearre (1980) had a ' $b$ ' value of only 0.283 , with smaller individuals consuming larger prey and larger individuals consuming smaller prey than in the present study. However, there is some controversy as to the correct identification of this species, which should probably be $S$. setosa (Pearre, 1980).

Cannibalism increased with size of the predator, as has been found by Stone (1969) and Pearre (1982). This is in contrast to the findings of Szyper (1978) and Feigenbaum (1979) who found the degree of cannibalism in S. enflata populations independent of chaetognath size. Pearre (1982) suggested that the low degree of cannibalism in young stages may be attributed to the difficulty of recognizing very young stage prey which lack the chaetae by which chaetognath prey are usually identified. Assuming equal handling costs, cannibalism was found to be energetically much more valuable to adult Sagitta friderici than consumption of single or multiple copepods (Table 5), since the chaetognath prey are generally larger than copepods and their contribution to the diet by dry weight or carbon is therefore much more significant.

Pearre (1982) noted chaetognath head width to be the best predictor of the degree of cannibalism in a given species. The head width/body length ratio of Sagitta friderici was 0.0526 (Table 1 ), indicating a small relative head size and suggesting a relatively low degree of cannibalism. In accordance with this, the overall proportion of adults displaying cannibalism was low $(2.4 \%)$, as in $S$. elegans $(0-3 \%$, Feigenbaum and Maris, 1984), which has a similar head width to body length ratio of 0.0517 (Pearre, 1982). Using Pearre's (1982) multiple regression equation relating cannibalism to predator size, the expected proportions of cannibalism for the larger three sizeclasses of Sagitta friderici in Table 3 would be $12.7 \%, 15.6 \%$ and $19.1 \%$ respectively. The discrepancy between these figures and the observed results, especially in the 9-10.99 mm and 11-12.99 mm size-classes may be explained by the low number of small Sagitta friderici available as prey (Fig. 2).

Feeding by adult Sagitta friderici occurred both during the day and at night, with no significant difference between the two sets of data $(p>0.05$, Mann-Whitney U-test). Since it is possible that the crustacean remains found in the guts during the day were actually ingested at night, a knowledge of the gut passage time of crustacean material is required. Several laboratory studies have been conducted to determine the digestion times of various chaetognath species consuming prey at different temperatures, which have been reviewed by Feigenbaum and Maris (1984). Using these data (ingestion of single copepod prey only), along with additional data by Nagasawa (1985) and Øresland (1987), we have plotted the relationship between digestion time and temperature for six different chaetognath species (Fig. 10). It is evident that the digestion time at any one temperature can be extremely variable due to the ingestion of copepods of different sizes $\left(4.9 \mathrm{~h}-11.7 \mathrm{~h}\right.$ at $6^{\circ} \mathrm{C}$, Øresland, 1987) and that variation between species may not be as great as within species. We therefore used these data to construct an exponential equation relating temperature to digestion time, as done 


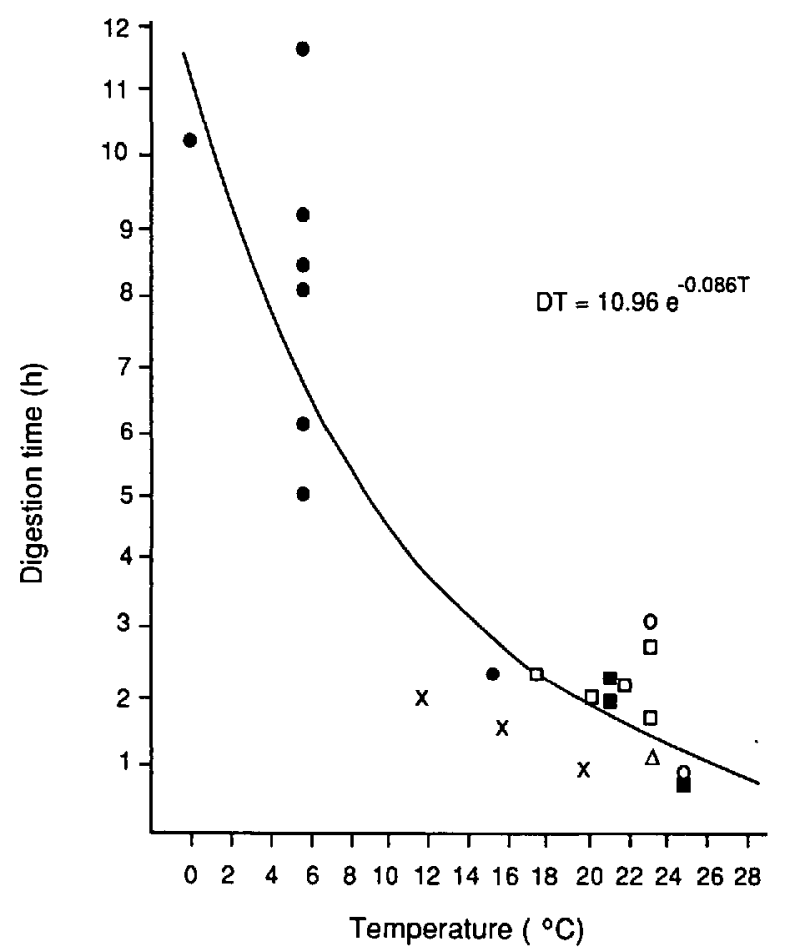

Figure 10. Digestion times $(h)$ of various chaetognath species consuming single copepods at different temperatures. Data obtained from Feigenbaum and Maris (1984), Nagasawa (1985) and Øresland (1987) and fitted by an exponential equation. - S.elegans; $O$, S.enflata; $\square$, S.crassa; $\mathbf{\square}$ S.hispida; X, S.setosa; $\triangle$, S.tenuis.

by Pearre $(1981,1982)$ for Sagitta elegans, resulting in the equation:

$$
t_{D}=10.96 e^{-0.086 \mathrm{~T}}(r=-0.86, n=22)
$$

where $t_{D}=$ digestion time in hours and $\mathrm{T}=$ temperature $\left({ }^{\circ} \mathrm{C}\right)$. This is remarkably similar to Pearre's equation $\left(t_{D}=10.24 e^{-0.0953 T}\right)$ and can be used to estimate the digestion time of Sagitta friderici during the day and night. The average mean depth occupied by the adult Sagitta population during the day was $54.3 \mathrm{~m}$, which had an average temperature of $10.2^{\circ} \mathrm{C}$, corresponding to a digestion time of $4.6 \mathrm{~h}$. Similarly, at night, the average mean depth was $37.1 \mathrm{~m}$ and the water temperature $13.5^{\circ} \mathrm{C}$, corresponding to a digestion time of $3.4 \mathrm{~h}$. From these calculations, it is evident that any crustacean remains found in Sagitta guts during the day (13h00-14h30) must have been consumed at depth during daylight hours.

The fact that feeding rates of Sagitta friderici (as reflected by the food containing ratio) did not follow any clear diurnal pattern, with food consumption taking place during the day and night, is consistent with the idea that the chaetognaths were not migrating in or out of a zone of high prey density to feed at night, but were rather 
migrating with their prey (see Fig. 4) and feeding more or less continuously. This pattern contrasts with that in other regions where marked diurnal patterns in feeding rates have been reported (Nagasawa and Marumo, 1972; Pearre, 1973; Szyper, 1978; Sullivan, 1980; Feigenbaum, 1982; Øresland, 1987), but is similar to that $S$. setosa (Drits and Utkina, 1988) and S. maxima (Sameoto, 1987) where there were no day/night differences. Two of the studies which reported diurnal feeding rhythms also reported chaetognath migration into copepod-rich surface layers to feed at night (Pearre, 1973; Sullivan, 1980), but unfortunately chaetognath migration patterns were not mentioned in the other studies. It is significant that the mesopelagic chaetognath S. maxima, which displayed no day/night feeding periodicity (Sameoto, 1987), also exhibited no diurnal vertical migrations, while $S$. setosa in the Black Sea migrated down to a 'plankton-rich' layer to feed during the day, and up to copepodrich surface waters to feed at night (Drits and Utkina, 1988). It would thus appear that the absence of a diurnal feeding rhythm may be correlated with either (a) chaetognaths migrating with their prey (as in the present study), (b) chaetognaths and prey both not migrating as in the case of meso- and bathypelagic species or (c) chaetognaths migrating from one prey-rich area during the day to another at night. It is interesting to note that the mesopelagic chaetognath $S$. zetesios displayed a 'reverse' diurnal feeding rhythm with feeding occurring at depth during the day, since this species consumed epipelagic organisms which migrate down from the upper layers during the day. (Terazaki and Marumo, 1982).

Despite the fact that the migration patterns of the adult Sagitta population closely followed that of the small and large calanoid copepods, there was no relationship between the abundance of prey and the percentage of chaetognaths containing food in their guts (Fig. 7). Pearre (1973) found that $S$. elegans fed at the copepod maxima, then when satiated, immediately sank down to deeper depths to digest their food. This sinking to digest food may also occur in Sagitta friderici, explaining the disparity between the proportion of chaetognaths containing food at each depth and the corresponding copepod density.

The number of copepods consumed by an average Sagitta adult per $24 \mathrm{~h}$-day can be estimated from Eq. 2, using the integrated number of copepods per chaetognath gut during the day (0.075) and night (0.078), as well as the estimated digestion times. The number of hours of daylight was taken as $10 \mathrm{~h}$, with $14 \mathrm{~h}$ of darkness. These calculations yield an ingestion rate of 0.48 copepods chaetognath ${ }^{-1} \mathrm{~d}^{-1}$ or $c a 8 \%$ body carbon $\mathrm{d}^{-1}$. This is comparable to predation rates of $0.2-1$ copepods $\mathrm{d}^{-1}$ for $S$. elegans and 0.5 copepods $\mathrm{d}^{-1}$ for $S$. maxima (Sameoto, 1987) as well as to ingestion rates of Eukrohnia hamata (5-11\% body dry weight $\mathrm{d}^{-1}$, Øresland, 1990). It is difficult to estimate the predatory impact of the chaetognath population on copepod stocks because of the disparities between depth of capture of the chaetognaths and that of their prey. Nevertheless, an estimate of the predatory impact of the Sagitta friderici population can be obtained from the mean numbers of copepods and chaetognaths 
Table 6. Numbers $\left(\mathrm{m}^{-2}\right)$ of copepods (in three categories) during each sampling period, as well as total copepod and chaetognath numbers $\mathrm{m}^{-3}$, averaged over the entire water column. An estimate of the percentage of the copepod standing stock consumed by the Sagitta friderici population per day is also indicated.

$\begin{array}{ccccccc}\text { Time } & \begin{array}{c}\text { Cyclopoids } \\ \text { no.m }^{-2}\end{array} & \begin{array}{c}\text { Small } \\ \text { Calanoids } \\ \text { no.m }\end{array} & \begin{array}{c}\text { Large } \\ \text { Calanoids } \\ \text { no.m }\end{array} & \begin{array}{c}\text { Total } \\ \text { Copepods } \\ \text { no.m }\end{array} & \begin{array}{c}\text { Total } \\ \text { Chaetognaths } \\ \text { no.m }^{-3}\end{array} & \text { \% Consumed } \\ \text { 19h06 } & 32423 & 74171 & 32204 & 2135 & 48 & 1.08 \\ \text { 00h22 } & 36545 & 96867 & 54219 & 2744 & 133 & 2.32 \\ \text { 06h35 } & 25052 & 38144 & 29144 & 1409 & 54 & 1.84 \\ \text { 13h14 } & 28491 & 71874 & 8576 & 1556 & 35 & 1.08 \\ \text { 21h30 } & 32392 & 54945 & 36607 & 1771 & 194 & 5.26 \\ \text { 00h36 } & 62603 & 107344 & 31908 & 2968 & 207 & 3.35 \\ \text { 07h57 } & 73159 & 90139 & 16452 & 2765 & 126 & 1.00 \\ \text { 14h32 } & 85966 & 73977 & 2804 & 2260 & 47 & 1.00\end{array}$

$\mathrm{m}^{-3}$ at each sampling time (Table 6), using an average of 0.48 prey chaetognath ${ }^{-1}$ day $^{-1}$. Total chaetognath numbers (adults and juveniles) ranged from $35-207 \mathrm{~m}^{-3}$ while that of the copepods (excluding the very large Rhincalanus) ranged from $1409-2765 \mathrm{~m}^{3}$. Corresponding predation rates by the chaetognath population resulted in $1.00-5.26 \%$ of the copepod community being consumed per day. Interestingly, this is similar to the predation rates of Euphausia lucens adults in the same area, which were estimated to consume 2.4-7.3\% of the copepod standing stock per day (Stuart and Pillar, 1990). Despite the fact that daily consumption rates by the euphausiids were much higher (17.6 copepods adult ${ }^{-1} \mathrm{~d}^{-1}$ ) predation rates were comparable to those of the chaetognaths since euphausiid densities were much lower $\left(8.3 \mathrm{~m}^{-3}\right)$. Similarly, Drits and Utkina (1988) estimated that $S$. setosa in the Black Sea consumed $0.3-5 \%$ and $0.5-6 \%$ of the standing stocks of Calanus (stage V) and Pseudocalanus respectively. However, as pointed out by Mironov (1960) it is not really correct to compare predation (a rate process) with a standing stock, but rather with copepod production (also a rate process). Using the copepod production figures of Verheye (1991) for this area $\left(4.8 \mathrm{mg} \mathrm{C} \mathrm{m}^{-3} \mathrm{~d}^{-1}\right)$, and the mean size of copepod ingested $(0.95 \mathrm{~mm}$ prosome length $=6.80 \mu \mathrm{g} \mathrm{C})$, this would correspond to 2.38 $14.06 \%$ of the copepod production being consumed per day by the chaetognath population. Thus it is obvious that the chaetognath community in the southern Benguela upwelling region exerts a significant impact on the copepod community as a whole, and perhaps an even greater predatory impact on individual copepod species.

Acknowledgments. We thank Dr M. Gibbons and two anonymous referees for constructive comments on the manuscript, as well as Jillian Burbidge and Isolda Rojas for technical assistance. V.S. was funded by a grant for the Benguela Ecology Programme from the South African National Committee for Oceanographic Research (SANCOR). We would also like to 
thank the Director of the Sea Fisheries Research Institute for funds and facilities for this research and the officers and crew of the R.S. Africana.

\section{REFERENCES}

Armstrong, D. A., H. M. Verheye and A. D. Kemp. 1991. Short-term variability during an anchor station study in the Southern Benguela upwelling system: fecundity estimates of the dominant copepod, Calanoides carinatus. Prog. Oceanogr., 28 (in press).

Bajov, A. D. 1935. How to estimate the daily food consumption of fish under natural conditions. Trans. Amer. Fish. Soc., 65, 288-289.

Cheney, J. 1985. Spatial and temporal abundance patterns of oceanic chaetognaths in the western North Atlantic II. Vertical distributions and migrations. Deep-Sea Res., 32, 1061-1075.

David, P. M. 1958. The distribution of chaetognatha of the southern ocean. Discovery Reports, 29, 199-228.

Drits, A. V. and S. V. Utkina. 1988. Feeding of Sagitta setosa in the layers of daytime phytoplankton accumulation in the Black Sea. Oceanology, 28, 781-785.

Feigenbaum, D. L. 1979. Daily ration and specific daily ration of the chaetognath Sagitta enflata. Mar. Biol., 54, 75-82.

- 1982. Feeding by the chaetognath, Sagitta elegans, at low temperatures in Vineyard Sound, Massachusetts. Limnol. Oceanogr., 27, 699-706.

Feigenbaum, D. L. and R. C. Maris. 1984. Feeding in the Chaetognatha, in Oceanography and Marine Biology Annual Review, 22, Barnes, M. ed., Aberdeen University Press, Aberdeen, 343-392.

Gibbons, M. J. 1991. Diel feeding and vertical migration of Sagitta serratodentata Krohn tasmanica Thomson (Chaetognatha) in the southern Benguela, J. Plank. Res., (in press.)

Gibbons, M. J., S. C. Pillar and V. Stuart. 1991. Selective carnivory by Euphausia lucens. Cont. Shelf Res., (in press.)

Heydorn, A. E. F. 1959. The chaetognatha off the west coast of the union of South Africa. Un. of S.A. Dept. Comm. \& Industries. Investl. Report no. 36, 1-56.

Huntley, M. and E. R. Brooks. 1982. Effects of age and food availability on diel vertical migration of Calanus pacificus. Mar. Biol., 71, 23-31.

James, A. G. 1987. Feeding ecology, diet and field-based studies on feeding selectivity of the cape anchovy Engraulis capensis Gilchrist. S. Afr. J. Mar. Sci., 5, 673-692.

Kuhlmann, D. 1977. Laboratory studies on the feeding behaviour of the chaetognaths Sagitta setosa J. Muller and S. elegans Verill with special reference to fish eggs and larvae as food organisms. Meereforschung, 25, 163-171.

Lough, R. G. and R. W. Trites. 1989. Chaetognaths and oceanography on Georges Bank. J. Mar. Res., 47, 343-369.

Mironov, G. N. 1960. Feeding of plankton predators II. Feeding of Sagitta (Russ.). Trud. Sevastopol Biol. Sta., 13, 78-88.

Nagasawa, S. 1985. The digestive efficiency of the chaetognath Sagitta crassa Tokioka, with observations on the feeding process. J. Exp. Mar. Biol. Ecol., 87, 271-281.

Nagasawa, S. and R. Marumo. 1972. Feeding of a pelagic chaetognath, Sagitta nagae Alvariño in Surugo Bay, Central Japan. J. Oceanogr. Soc. Japan, 28, 181-186.

$\emptyset$ resland, V. 1987. Feeding of the chaetognaths Sagitta elegans and $S$. setosa at different seasons in Gullmarsfjorden, Sweden. Mar. Ecol. Prog. Ser., 39, 69-79.

- 1990. Feeding and predation impact of the chaetognath Eukrohnia hamata in Gerlache Straight, Antarctic Peninsula. Mar. Ecol. Prog. Ser., 63, 201-209. 
Parsons, T. R., Y. Maita and C. M. Lalli. 1984. A Manual of Chemical and Biological Methods for Seawater Analysis. Pergamon Press, Oxford.

Pearre, S. 1973. Vertical migration and feeding in Sagitta elegans Verril. Ecology, 54, 300-314. - 1974. Ecological studies of three west Mediterranean chaetognaths. Inv. Pesq., 38, 325-369.

-1976. A seasonal study of the diets of three sympatric chaetognaths. Inv. Pesq., 40, 1-16. 1979. Problems of detecting and interpretation of vertical migration. J. Plank. Res., 1 , $29-44$.

1980. Feeding by chaetognatha: The relation of prey size to predator size in several species. Mar. Ecol. Prog. Ser., 3, 125-134.

- 1981. Feeding by chaetognatha: Energy balance and importance of various components of the diet of Sagitta elegans. Mar. Ecol. Prog. Ser., 5, 45-54.

1982. Feeding by chaetognatha: Aspects of inter- and intra-specific predation. Mar. Ecol. Prog. Ser., 7, 33-45.

Peterson, W. T., S. J. Painting and L. Hutchings. 1990. Diel variation in gut pigment content, diel vertical migration and estimates of grazing impact for copepods in the southern Benguela upwelling region in October, 1987. J. Plank. Res., 12, 259-281.

Pillar, S. C., D. A. Armstrong and L. Hutchings. 1989. Vertical migration, dispersal and transport of Euphausia lucens in the southern Benguela current. Mar. Ecol. Prog. Ser., 53, 179-190.

Pillar, S. C. and V. Stuart. 1988. Population structure, reproductive biology and maintenance of Euphausia lucens in the southern Benguela current. J. Plank. Res., 10, 1083-1098.

Raymont, J. E. G. 1983. Plankton and productivity in the oceans, in Zooplankton Vol. 2, 2nd ed., Pergamon Press, Oxford, 824 pp.

Reeve, M. R. 1980. Comparative experimental studies on the feeding of chaetognaths and ctenophores. J. Plank. Res., 2, 381-393.

Sameoto, D. D. 1987. Vertical distribution and ecological significance of chaetognaths in the arctic environment of Baffin Bay. Polar. Biol., 7, 317-328.

Simmard, Y., G. Lacroix and L. Legendre. 1985. In situ twilight grazing rhythm during diel vertical migrations of a scattering layer of Calanus finmarchicus. Limnol. Oceanogr., 30, 598-606.

- 1986. Diel vertical migrations and nocturnal feeding of a dense coastal krill scattering layer (Thysanoessa raschi and Meganyctiphanes norvegica) in stratified surface waters. Mar. Biol., 91, 93-105.

Stone, J. H. 1965. The Chaetognatha community of the Agulhas current; its structure and related properties. Ph.D. thesis, University of Cape Town, South Africa.

- 1969. The chaetognatha community of the Agulhas current: its structure and related properties. Ecol. Monogr., 39, 433-463.

Stuart, V. 1986. Feeding and metabolism of Euphausia lucens (Euphausiacea) in the southern Benguela current. Mar. Ecol. Prog. Ser., 30, 117-125.

- 1989. Observations on the feeding of Euphausia lucens on natural phytoplankton suspensions in the southern Benguela upwelling region. Cont. Shelf. Res., 9, 1017-1028.

Stuart, V. and S. C. Pillar. 1988. Growth and production of Euphausia lucens in the southern Benguela current. J. Plank. Res., 10, 1099-1112.

_ 1990. Diel grazing patterns of all ontogenetic stages of Euphausia lucens and in situ predation rates on copepods in the southern Benguela Upwelling region. Mar. Ecol. Prog. 
Sullivan, B. K. 1977. Vertical distribution and feeding of two species of chaetognaths at Weather Station "P." Ph.D. thesis, Oregon State University, USA, 100 pp.

1980. In situ feeding behaviour of Sagitta elegans and Eukrohnia hamata (Chaetognatha) in relation to the vertical distribution and abundance of prey at Ocean Station "P." Limnol. Oceanogr., 25, 317-326.

Szyper, J. P. 1978. Feeding rate of the chaetognath Sagitta enflata in nature. Est. Coastal Mar Sci., 7, 567-575.

Terazaki, M. and R. Marumo. 1982. Feeding habits of meso- and bathypelagic chaetognatha, Sagitta zetesios Fowler. Oceanologica Acta, 5, 461-464.

Verheye, H. M. 1989. Distribution, dynamics and production of the copepod Calanoides carinatus (Kroyer, 1849) in the southern Benguela upwelling region. Ph.D. thesis, University of Cape Town, South Africa, $238 \mathrm{pp}$.

1991. Short-term variability during an anchor station study in the southern Benguela upwelling system: Abundance, distribution and estimated production of mesozooplankton with special reference to Calanoides carinatus (Kroyer, 1849). Prog. Oceanogr., 28 (in press.)

Verheye, H. M. and J. G. Field. 1991. Vertical distribution and diel vertical migration of Calanoides carinatus (Kroyer, 1849) developmental stages in the southern Benguela upwelling region. J. Exp. Mar. Biol. Ecol.,

Zo, Z. 1973. Breeding and growth of the chaetognath Sagitta elegans in Bedford Basin. Limnol. Oceanogr., 18, 750-756. 